\title{
Toward an Improved Air Pollution Warning System in Quebec
}

\author{
Pierre Masselot ${ }^{1, *} \mathbb{B}$, Fateh Chebana ${ }^{1}$, Éric Lavigne ${ }^{2,3}$, Céline Campagna ${ }^{1,4}$, Pierre Gosselin $1,4,5$ \\ and Taha B.M.J. Ouarda ${ }^{1}$ \\ 1 Institut National de la Recherche Scientifique, Centre Eau-Terre-Environnement, 490, rue de la Couronne, \\ Québec, QC G1K 9A9, Canada; fateh.chebana@ete.inrs.ca (F.C.); celine.campagna@inspq.qc.ca (C.C.); \\ pierre.gosselin@inspq.qc.ca (P.G.); taha.ouarda@ete.inrs.ca (T.B.M.J.O.) \\ 2 School of Epidemiology and Public Health, University of Ottawa, 600 Peter Morand Crescent, \\ Ottawa, ON K1G 5Z3, Canada; eric.lavigne@canada.ca \\ 3 Air health Science Division, Health Canada, 269 Laurier Ave West, Ottawa, ON K1A 0K9, Canada \\ 4 Institut National de Santé Publique du Québec, 945 Avenue Wolfe, Québec, QC G1V 5B3, Canada \\ 5 Ouranos, 550 Rue Sherbrooke Ouest, Montréal, QC H3A 1B9, Canada \\ * Correspondence: pierre.masselot@ete.inrs.ca; Tel.: +1-418-654-2696
}

Received: 2 May 2019; Accepted: 7 June 2019; Published: 13 June 2019

\begin{abstract}
The nature of pollutants involved in smog episodes can vary significantly in various cities and contexts and will impact local populations differently due to actual exposure and pre-existing sensitivities for cardiovascular or respiratory diseases. While regulated standards and guidance remain important, it is relevant for cities to have local warning systems related to air pollution. The present paper proposes indicators and thresholds for an air pollution warning system in the metropolitan areas of Montreal and Quebec City (Canada). It takes into account past and current local health impacts to launch its public health warnings for short-term episodes. This warning system considers fine particulate matter $\left(\mathrm{PM}_{2.5}\right)$ as well as the combined oxidant capacity of ozone and nitrogen dioxide $\left(\mathrm{O}_{\mathrm{x}}\right)$ as environmental exposures. The methodology used to determine indicators and thresholds consists in identifying extreme excess mortality episodes in the data and then choosing the indicators and thresholds to optimize the detection of these episodes. The thresholds found for the summer were $31 \mu \mathrm{g} / \mathrm{m}^{3}$ for $\mathrm{PM}_{2.5}$ and $43 \mathrm{ppb}$ for $\mathrm{O}_{\mathrm{x}}$ in Montreal, and $32 \mu \mathrm{g} / \mathrm{m}^{3}$ and $23 \mathrm{ppb}$ in Quebec City. In winter, thresholds found were $25 \mu \mathrm{g} / \mathrm{m}^{3}$ and $26 \mathrm{ppb}$ in Montreal, and $33 \mu \mathrm{g} / \mathrm{m}^{3}$ and $21 \mathrm{ppb}$ in Quebec City. These results are in line with different guidelines existing concerning air quality, but more adapted to the cities examined. In addition, a sensitivity analysis is conducted which suggests that $\mathrm{O}_{\mathrm{x}}$ is more determinant than $\mathrm{PM}_{2.5}$ in detecting excess mortality episodes.
\end{abstract}

Keywords: warning system; air pollution; respiratory diseases; cardiovascular diseases; mortality; threshold

\section{Introduction}

Air pollution is a major public health issue with number of epidemiological studies reporting impact of diverse air pollutant on both mortality and morbidity [1]. In particular, respiratory and cardiovascular diseases are particularly impacted by air pollution $[2,3]$. The most studied pollutants are fine particulate matters $\left(\mathrm{PM}_{2.5}\right)[4,5]$, ozone $\left(\mathrm{O}_{3}\right)$ [6], and nitrogen dioxide $\left(\mathrm{NO}_{2}\right)$ [7].

$\mathrm{PM}_{2.5}$ is an important cause of respiratory and cardiovascular diseases, by penetrating into the respiratory system [8]. Emissions of $\mathrm{PM}_{2.5}$ are mainly caused by fossil fuel combustion, but can also originate from wildfire smoke $[9,10] . \mathrm{O}_{3}$ originates from chemical reactions in the atmosphere which are catalyzed by solar radiation, and is thus more prominent during summer. It may exacerbate respiratory diseases such as asthma $[11,12]$. $\mathrm{NO}_{2}$ is generated by combustion with a prominent source 
being motorized vehicles, especially in a place like the province of Quebec where electric power generation comes mainly from hydraulic sources, including home heating.

Adverse effects of air pollution led many public health authorities to implement early-warning systems [13]. Such systems have been implemented in many developed countries such as the UK, United States, and France. Intensive research is also currently conducted in China to improve the performances of early-warning systems $[14,15]$. In Quebec, air quality indicators and threshold guidelines are already used both at the Canadian $[16,17]$ and the provincial $[18]$ level.

Current early-warning systems usually involve the monitoring of an air quality index (AQI) and the use of a predefined threshold or scale (i.e., several thresholds) to inform the population of potential risks [13]. The focus of research on early warning systems usually concerns the improvement of AQI modelling and forecasting [19], which is nowadays accurate. However, much less attention is given to the choice of thresholds, which are mainly based on overall reviews of risk assessment [20] and are thus largely related to risk management. The main weakness of early-warning systems is thus that the thresholds do not necessarily accurately reflect the impact of AQIs or air pollutants on public health. Consequently, the thresholds and resulting guidelines are very similar from country to country and poorly reflect the local population characteristics or the actual mix of pollutants.

Recent reviews of air pollution and health impacts show wide worldwide variation of $\mathrm{PM}_{2.5}$ concentrations, with high variability in effect estimates across cities, up to an order of magnitude [21]. They also show, in the Canadian context, adverse effects of outdoor air pollution at concentrations that were below existing North American standards for children. Moreover, heterogeneous effects of air pollutants were found according to city, sex, socioeconomic status, and seasonality [22]. There seems to be specific impacts on the elderly but few studies have specifically addressed this context [23]. In addition, the health impact of each of these pollutants may vary according to the season, by interacting with temperature [24]. This diversity of the effects stresses the need to adapt local air pollution thresholds and guidelines to the population's distinctive characteristics, including health status.

Following this need, the present study proposes an air pollution-health warning system (APHWS) in the two largest cities of the province of Quebec: Montreal and Quebec City. This APHWS seeks to adapt indicators and thresholds to each city population, by not being based on general guidelines but on a data-based evaluation of the air pollution levels that lead to increased risks on health, and in particular mortality. Note that few studies sought to propose air pollution guidelines based on health, such as Cairncross et al. [25], which weighs the pollutants in the AQI based on estimated relative risks (RR) on health. Islam et al. [26] set a threshold for $\mathrm{PM}_{10}$ in the context of a global evaluation of climate warning thresholds for the Greater London. However, these ideas are based on the interpretation of a dose-lag-response relationship and not on the direct estimation of thresholds.

In the present study, we consider a methodology that allows estimating thresholds and indicators on historical data of air pollution and health endpoints. In particular, the methodology relates past records of important excess mortality events to high air pollution levels. This allows an accurate assessment of thresholds above which air pollution is considered an important threat for the population's health. The considered method is adapted from a previously proposed one in the context of heat-health warning systems (HHWS) [27]. In the heat context, such a method allowed an efficient prediction of excess mortality events [28] and the resulting HHWS effectively helped in reducing heat-related mortality during summer [29]. Thus, we expect similar benefits from its adaptation to the air pollution context.

\section{Materials and Methods}

\subsection{Data}

The data used in this study are those of the two main metropolitan areas of the province of Quebec: Quebec City and Montreal. As exposure indicators, daily maximum values of fine particulate matter $\left(\mathrm{PM}_{2.5}\right)$, ozone $\left(\mathrm{O}_{3}\right)$, and nitrogen dioxide $\left(\mathrm{NO}_{2}\right)$ are collected by the National Air Pollution 
Surveillance (NAPS) program of Environment and Climate Change Canada (ECCC). These three pollutants are chosen because they usually stand out in the impact of air pollution on health $[1,17]$. The time series used corresponds to the spatial mean of the measurement stations inside the two cities' metropolitan areas.

The proposed APHWS seeks to prevent extreme excess mortality events, which are rare by nature. It thus seems unlikely that these events occur while the three considered pollutants simultaneously show elevated values. This is notably due to the so-called curse of dimensionality [30]. Therefore, instead of directly using $\mathrm{O}_{3}$ and $\mathrm{NO}_{2}$, we compute their combined oxidant capacity $\left(\mathrm{O}_{\mathrm{x}}\right)$ as $\mathrm{O}_{x}=$ $\left(2.075 \times \mathrm{O}_{3}+1.07 \times \mathrm{NO}_{2}\right) / 3.145$ [31]. Indeed, it has been shown that considering $\mathrm{O}_{\mathrm{x}}$ is equivalent to considering both $\mathrm{O}_{3}$ and $\mathrm{NO}_{2}$ [32,33].

A preliminary analysis of air-pollution-related mortality also includes temperature and relative humidity. They are collected from the DayMet database maintained by the National Aeronautics and Space Administration (NASA). DayMet provides reanalyzed values for several meteorological variables on a spatial grid with a resolution of $1 \mathrm{~km}$. Grid points inside the ecumene of the metropolitan areas are averaged to obtain a single series for each city. Note that DayMet does not directly provide relative humidity but vapor pressure. The former is thus calculated from the latter using standard formulas [34].

The health impact of the APHWS is based on mortality series for which at least one of the causes (main or secondary) inherits from either cardiovascular (codes I10-I13, I15, I20-I25, I50 of the ICD10) or respiratory diseases (codes J00-J99 of the ICD10). These systems are the most vulnerable to air pollution and jointly considering them allows obtaining a large number of events [6]. These data were provided by the Institut national de santé publique du Québec (INSPQ).

Exposure and health data are jointly available from 1998 to 2014. However, the years 1998 and 1999 are omitted from the dataset to avoid issues related to the ICD change (from 9 to 10) in 2000, which results in a non-negligible breakpoint in the respiratory mortality series [35]. This leaves a total of 15 years of data. Since the association between air pollution and mortality vary with temperature, the APHWS is thus separated into two seasonal components: Summer (May to September) and winter (October to April). Thus, the final series lengths are $n_{s}=2295$ days and $n_{w}=3184$ days, respectively. Table 1 shows the mean daily values of each variable considered in the present study for Montreal and Quebec City and for both summer and winter.

Table 1. Mean daily values of each variable considered in the present study. $\mathrm{PM}_{2.5}=$ fine particle matters; $\mathrm{O}_{\mathrm{x}}=$ combined oxidant capacity of ozone and nitrogen dioxide.

\begin{tabular}{ccccc}
\hline \multirow{2}{*}{ Variable } & \multicolumn{2}{c}{ Montreal } & \multicolumn{2}{c}{ Quebec City } \\
\cline { 2 - 5 } & Summer & Winter & Summer & Winter \\
\hline Mortality count & 33.6 & 39.5 & 3.1 & 3.9 \\
Max PM $_{2.5}\left(\mu \mathrm{g} / \mathrm{m}^{3}\right)$ & 18.4 & 19.9 & 17.3 & 19.7 \\
Max $\mathrm{O}_{\mathrm{x}}(\mathrm{ppb})$ & 28.1 & 22.0 & 24.9 & 23.9 \\
Temperature $\left({ }^{\circ} \mathrm{C}\right)$ & 17.9 & -1.0 & 14.4 & -4.3 \\
Relative humidity $(\%)$ & 67.0 & 69.0 & 65.1 & 66.6 \\
\hline
\end{tabular}

\subsection{Statistical Methodology}

The considered statistical methodology was initially developed for France's HHWS [36] and thereafter generalized and adapted to the province of Quebec [27]. The goal of this methodology is to determine two couples of indicators $Z_{t}^{(j)}$ and thresholds $s^{(j)}$ on air pollutants (where $j$ stands for $\mathrm{PM}_{2.5}$ or $\mathrm{O}_{\mathrm{x}}$ ) such that when both $\mathrm{Z}_{t}^{(j)}>s^{(j)}$, day $t$ is considered as an alarm. They are determined through the four following steps, which are then described with more details below:

1. Choose maximum lags for air pollution indicators;

2. Compute an excess mortality (EM) series from the mortality data; 
3. Determine extreme EM episodes as targets of the APHWS;

4. Choose the best indicators-thresholds combination.

Note that each of these steps is performed once for each seasonal APHWS and for each city.

\subsubsection{Choose Maximum Lags for Air Pollution Indicators}

In the present APHWS, we consider indicators $Z_{t}^{(j)}$ as weighted means of past daily pollutant values, i.e.,:

$$
Z_{t}^{(j)}=\sum_{l=0}^{L} \alpha_{l} X_{t-l}^{(j)}
$$

where $X_{t}^{(j)}$ are daily values of air pollutant $j\left(\mathrm{PM}_{2.5}\right.$ or $\left.\mathrm{O}_{\mathrm{x}}\right)$ and $\alpha_{l}$ are weights to be optimized. We constrain the weights such that $\sum_{l} \alpha_{l}=1$ and $\alpha_{0} \geq \alpha_{1} \geq \ldots \geq \alpha_{\mathrm{L}}$. The latter constraint accounts that the APHWS will be running on forecast data ( 0 to 3 days) and therefore ensures that the importance of each daily forecast in the indicator decreases with the horizon.

The purpose of the first step is to determine the value of the maximum lag $L$ in Equation (1) through a preliminary analysis. It can be chosen by fitting a distributed lag nonlinear model (DLNM) [37]. A DLNM accounts for both measured and unmeasured confounders (by opposition to more common methods such as the cross-correlation function) and yields a lag-response relationship to visually choose $L$. Here, quasi-Poisson DLNMs are fitted with penalized splines on the variable dimension [38] and natural splines on the lag dimension. The latter includes lags from 0 to 5 days, with interior knots at lags 1 and 2 to account for the very short-term acute effect of air pollution indicators on mortality [4]. Smooth spline components of time are used to account for unmeasured confounder, one for the day of season with four degree of freedoms and one for the long-term trend with one degree of freedom per decade as in, e.g., Gasparrini et al. [39]. Weather confounding is also accounted for, by including temperature and relative humidity both averaged over the three previous days. Temperature is included in a natural spline with three degrees of freedom to model the U-shaped relationship, and relative humidity is included in a linear fashion [32,40].

\subsubsection{Compute an Excess Mortality Series}

The excess mortality (EM) series represents excess death from a baseline of expected mortality. It is computed as:

$$
E M_{t}=\frac{Y_{t}-B_{t}}{B_{t}} \times 100
$$

where $Y_{t}$ is the observed mortality series and $B_{t}$ is the mortality baseline, i.e., the expected mortality without influence of the exposure of interest. $B_{t}$ is estimated in a standard manner, i.e., through natural cubic splines with eight degrees of freedom per year. It accounts for seasonal variations and the long-term trend of mortality.

\subsubsection{Determine Significant Excess Mortality Episodes}

The role of this step is to choose the magnitude of EM (as defined in Equation (2)) to be detected by the APHWS. This is translated by choosing a preliminary threshold $s_{O M}$ on EM and considering that all days for which EM exceeds this threshold are extremes. This threshold can vary by location. It ought to be a compromise between a sufficient number of EM extremes and important enough extremes which are not due to statistical fluctuations.

Since extreme EM days tend to occur in clusters [41], we consider any cluster as an EM episode. Episodes are hereby defined as a cluster of EM extremes separated by less than three days from each other, with the addition of the three days preceding and the three days following the cluster of extremes. In practice, we consider that an EM episode is successfully detected if at least one of its days is detected. It allows accounting for the temporal dependence between extreme days. 
Finally, an additional constraint is added to stipulate that the same day maximum $\mathrm{PM}_{2.5}$ exceeds the value of $25 \mu \mathrm{g} / \mathrm{m}^{3}$. This ensures that the EM episode is related to high levels of air pollution and not only to potentially confounding events, such as heat waves or cold spells. The preliminary value of $25 \mu \mathrm{g} / \mathrm{m}^{3}$ is based on the regulatory criteria advised by the World Health Organisation [19] as an acceptable prior.

\subsubsection{Choose the Best Combination of Indicators-Thresholds}

In this final step of the methodology, the optimal indicator weightings $\alpha_{l}$ (in Equation (1)) and threshold $s$ are chosen. Different weighting and threshold combinations are tested and, for each of them, resulting alarm days are compared to the actual EM episodes determined in step 3. For given weights (constrained as explained in Section 2.2.1) and thresholds, alarm days $t$ are determined such that $Z_{t}^{(j)}>s^{(j)}$ for each indicator. It includes all days which would have been set as alerts considering chosen weights and thresholds.

The relevancy of weightings and threshold can be evaluated by comparing the obtained alarms with the episodes extracted in step 3 (Section 2.2.3). Two criteria are considered: (1) Sensitivity, which is the proportion of actual EM episodes (determined in the previous step) that are correctly detected by the APHWS and (2) the number of false alarms (FA) which are false positive episodes. Note that, even though a specificity score is usually used in binary classification [36], in the present case, the very low number of extremes lead to specificity scores always very close to 1 . Specificity is thus not very informative and the number of FA is preferred to evaluate the accuracy of an APHWS. The chosen weightings and thresholds should represent a trade-off between high sensitivity and low number of false alarms. We nonetheless attribute a larger importance to sensitivity since the APHWS is intended for public health authorities which decide to actually perform actions whenever the APHWS gives them a signal.

\section{Results}

The focus of the present section is on the results of Montreal to show the process of choosing thresholds and indicators for the APHWS. However, figures and tables showing results for Quebec City can be found in the Supplementary Materials (Figures S1-S3 as well as Tables S1 and S2).

\subsection{Results for Montreal's APHWS}

\subsubsection{Choice of Lags}

Figure 1 shows the lag-response relationships between the pollutants and mortality at the values $\mathrm{PM}_{2.5}=25 \mu \mathrm{g} / \mathrm{m}^{3}$ and $\mathrm{O}_{x}=50 \mathrm{ppb}$. These levels correspond to previous guidelines on adverse effects of these indicators on health. Note that the whole DLNM surface can be found in the Supplementary Material (Figure S4) but brings little additional information since the dose-response relationship is quasilinear. In summer for $\mathrm{PM}_{2.5}$, Figure 1a suggests a relative risk (RR) which significantly differs from 1 on the same day only (lag 0 ), but also in a non-negligible way at lag 1 . The RR then rapidly decreases toward 1 when the lag increases. We chose $L=1$ for the $\mathrm{PM}_{2.5}$ indicator in the summer APHWS to avoid underestimating its impact on mortality [4]. Figure $1 \mathrm{~b}$ shows that the lag-response relationship with $O_{x}$ is the largest at lag 1 and is very close to $R R=1$ for lags larger than 1 , with the exception of lag 5 which could be a boundary effect of the model. In summer, the chosen maximum lag for the $\mathrm{O}_{\mathrm{x}}$ indicator is then also $L=1$.

In winter, Figure $1 \mathrm{c}$ shows that the RR of $\mathrm{PM}_{2.5}$ is at his highest at lag 1 and then RR immediately shrinks toward 1. Although the $R R$ of $\mathrm{O}_{\mathrm{x}}$ is close to 1 at all lags, we nonetheless chose an indicator with lag 1 for the $\mathrm{O}_{\mathrm{x}}$ indicator in winter since prior research showed that it could also have an impact at lag 1 [32]. To summarize, all indicators considered in the following are two-day weighted means of pollutants, i.e., considering lags 0 and 1. 
a) Summer, $\mathrm{PM}_{2.5}$

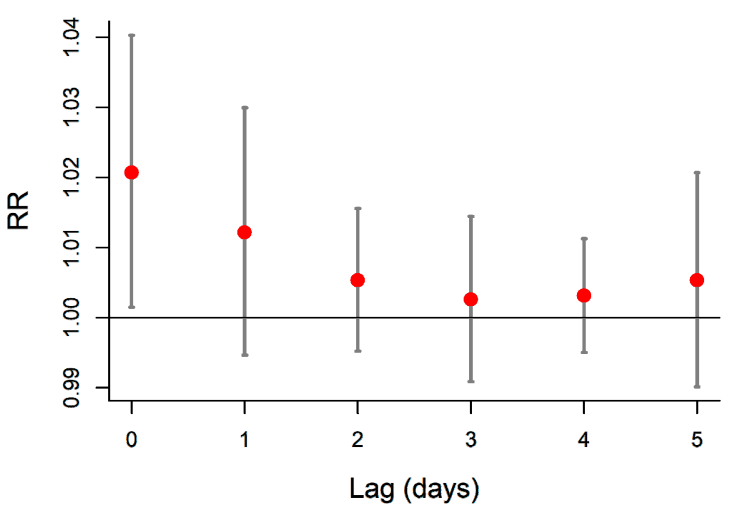

c) Winter, $\mathrm{PM}_{2.5}$

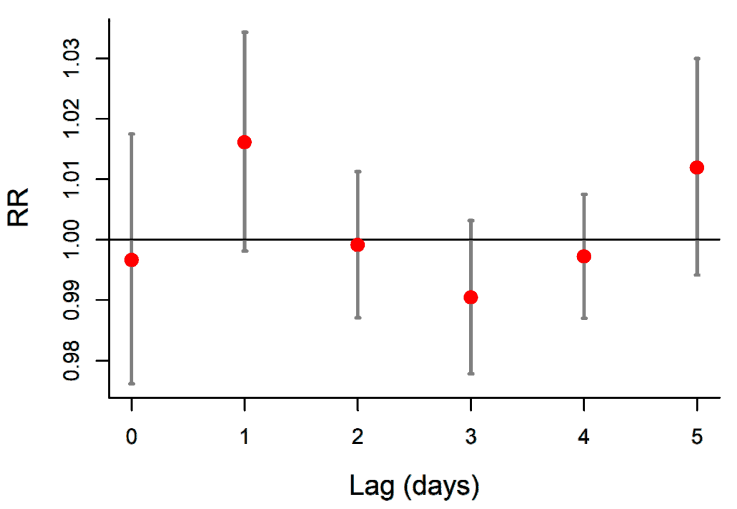

b) Summer, $O_{x}$

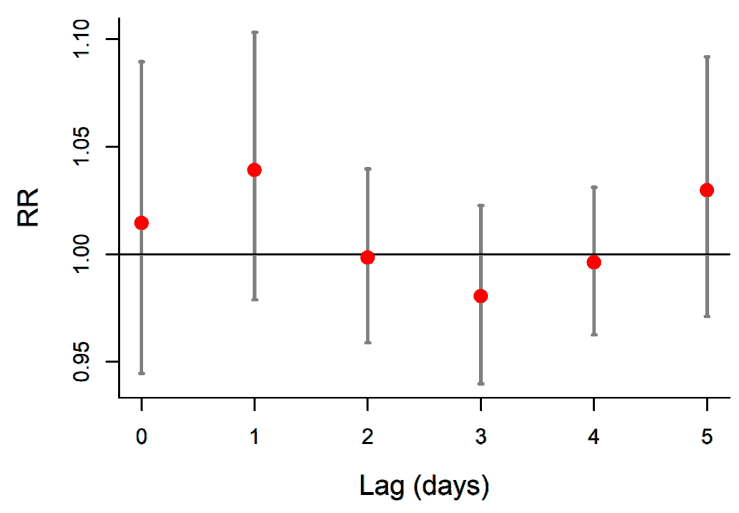

d) Winter, $O_{x}$

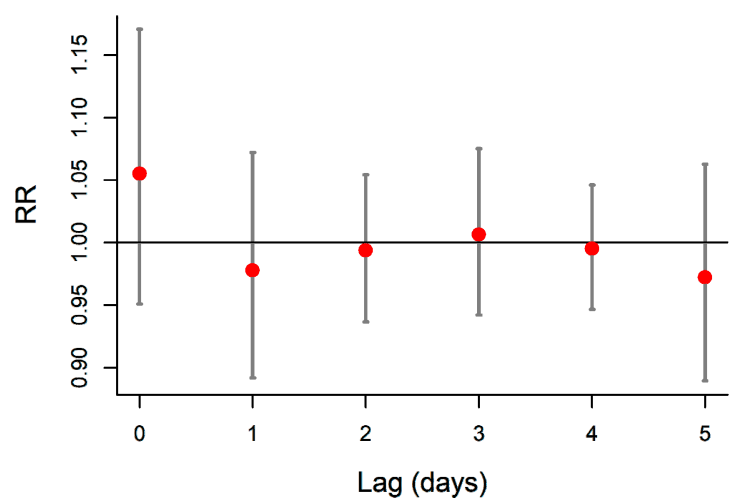

Figure 1. Lag-response relationship between mortality and $(\mathbf{a}, \mathbf{c}) \mathrm{PM}_{2.5}$ and $(\mathbf{b}, \mathbf{d}) \mathrm{O}_{\mathrm{x}}$ in Montreal. These curves correspond to the slice of the distributed lag nonlinear model (DLNM) surface at values $\mathrm{PM}_{2.5}=25 \mu \mathrm{g} / \mathrm{m}^{3}$ and $\mathrm{O}_{x}=50 \mathrm{ppb}$. Gray bars indicate $95 \%$ confidence intervals. $\mathrm{RR}=$ relative risk.

\subsubsection{Excess Mortality Episodes}

Step 2 of the procedure is to compute EM using Equation (2). Summary statistics of estimated EM are shown in Table 2. It shows that the baseline estimates well the expected mortality since EM series are centered at $0 \%$. EM distribution is similar between summer and winter with slightly lower variations in winter than in summer. This is especially true at extreme values since the maximum observed EM in summer is $110.4 \%$ while the maximum in winter is $58.8 \%$. These maxima correspond respectively to the 8 July 2010 which occurred during a major heat wave [42], and to the 9 November 2013 which does not seem to correspond to a particular event.

Table 2. Descriptive statistics of the estimated excess mortality (EM) for the period 2000-2015 in Montreal, expressed in percentage (\%). Summer spans the months May-September and winter the months October-April.

\begin{tabular}{cccccccc}
\hline & Minimum & 1st Quartile & Median & Mean & 3rd Quartile & Maximum & Standard Deviation \\
\hline Summer & -52.4 & -13.4 & -0.7 & 0.1 & 11.6 & 110.4 & 18.3 \\
Winter & -47.5 & -11.2 & -0.6 & 0.0 & 10.4 & 58.8 & 16.1 \\
\hline
\end{tabular}

Step 3 consists of choosing the preliminary threshold $s_{O M}$ indicating the minimum EM above which a day is considered as an EM extreme. Figure 2 indicates the number of episodes found in the data according to different $s_{O M}$ values for summer and winter. Recall that an episode may contain several exceeding days if they are closer than three days from each other. Figure 2a shows that, in summer, for $s_{O M}<50 \%$, the number of episodes associated with important $\mathrm{PM}_{2.5}$ is much lower than 
the sole number of episodes (without constraint). However, above $50 \%$, the majority of the episodes are associated with an amount of $\mathrm{PM}_{2.5}$ larger than $25 \mu \mathrm{g} / \mathrm{m}^{3}$. The value $s_{O M}=50 \%$ is thus chosen for summer as the preliminary threshold to determine significant EM episodes.

a) Summer

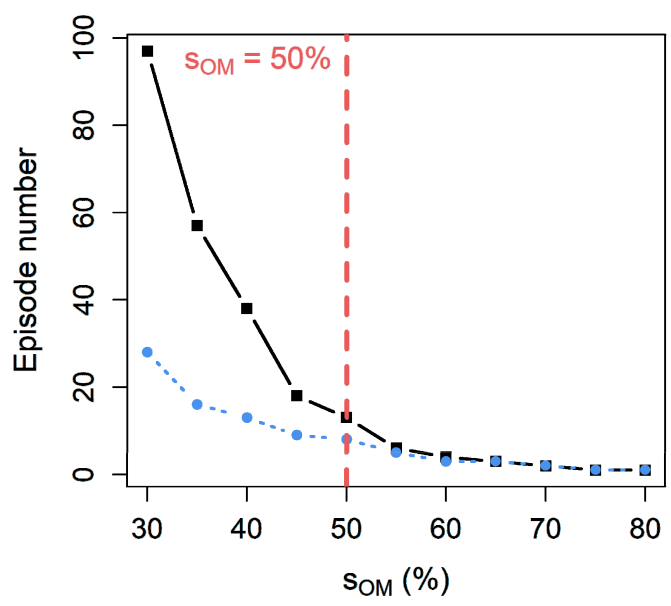

b) Winter

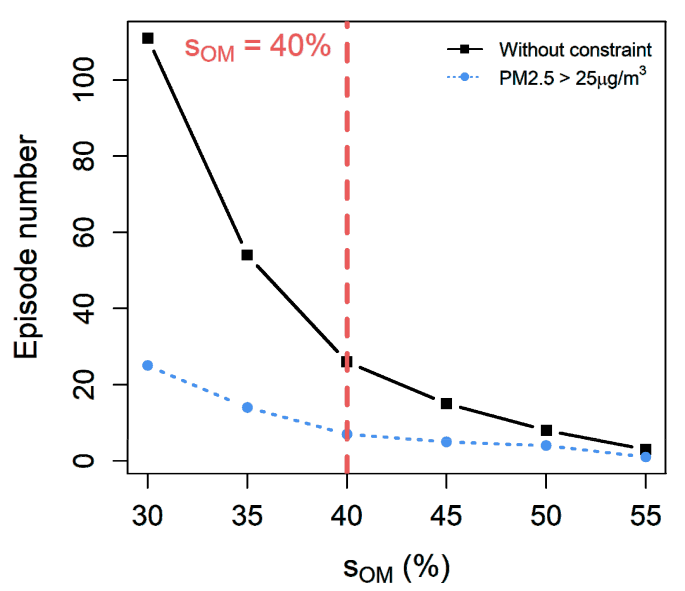

Figure 2. Number of EM episodes according to the chosen preliminary EM threshold $s_{O M}$.

In winter, Figure $2 b$ indicates that a large number of EM episodes are not linked to important amount of air pollution. The blue curve showing the number of episodes with $\mathrm{PM}_{2.5}$ larger than $25 \mu \mathrm{g} / \mathrm{m}^{3}$ rapidly decreases until $s_{O M}=40 \%$. We therefore chose $s_{O M}=40 \%$ for winter, which is slightly lower than in summer, consistently with the summary statistics of EM shown in Table 2.

Figure 3 shows the episodes identified with the thresholds $s_{O M}=50 \%$ in summer and $s_{O M}=40 \%$ in winter. Although summer is hereby shorter than winter, overall, more episodes are detected in the former, i.e., eight episodes in summer and seven in winter. This may be due to the synergy between temperature and pollution for which a growing body of evidence exists [24,43]. Indeed, among the eight summer episodes, four of them (the 2nd, 3rd, 4th, and 8th) have been already detected in a heat wave context [44] and correspond to the highest EM values. For instance, the deadly heat wave of July 2010 is clearly identifiable as the 8th episode. Note also that the 4 th episode corresponds to the important forest fires of July 2002 [45]. Supplementary details about the identified episodes are given in Tables S3 and S4 (Supplementary Materials).

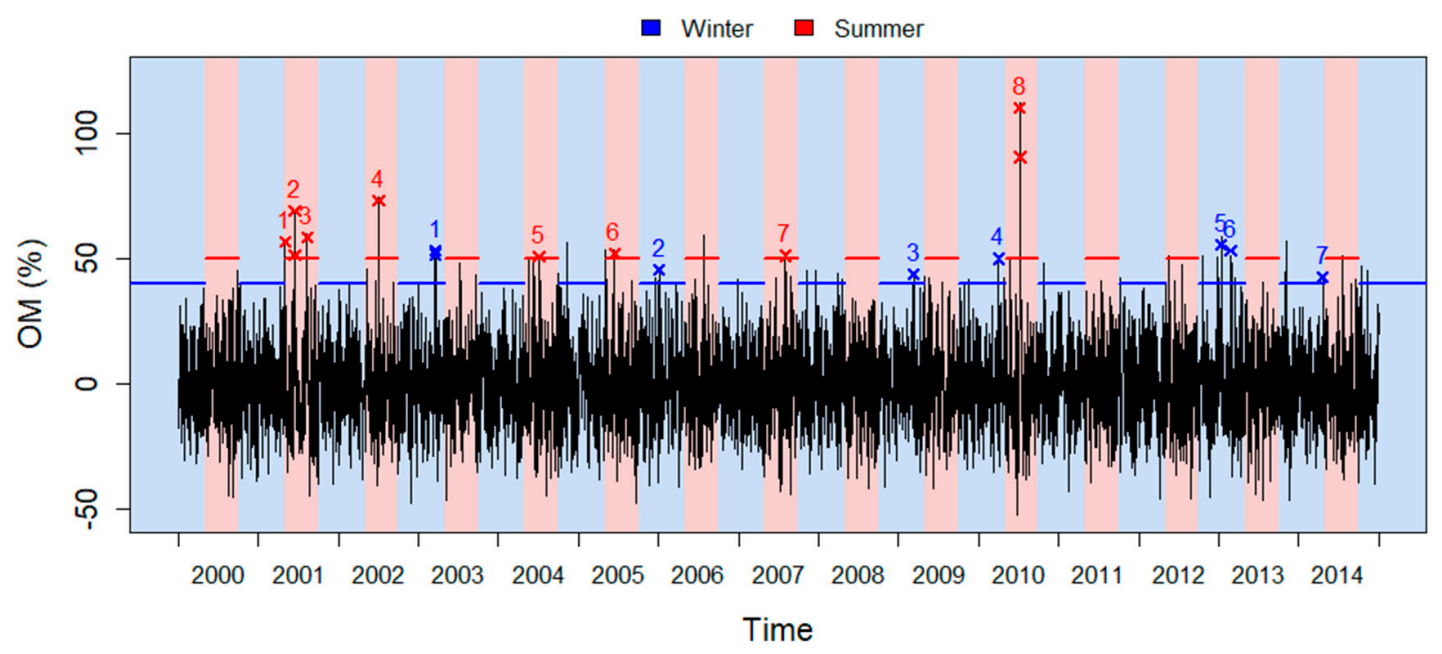

Figure 3. EM series with the identification of EM episodes. Crosses indicate extreme EM days (exceeding $s_{O M}$ ) and the number identifies episodes. Horizontal segments identify $s_{O M}$. Red areas identify summer and blue ones winter. Note that nonextreme days extending the episodes are not identified here for clarity purposes. 


\subsubsection{Final Indicators and Thresholds}

The results for different indicator weightings $\alpha_{l}$ and thresholds $s$ with associated scores are shown in Tables S5 and S6 for summer and winter respectively (Supplementary Materials) and the chosen ones are shown in Table 3. The rationale for choosing final indicators and thresholds is based on episodes: The chosen system should be a trade-off between an episode sensitivity close to one and a low number of episodes.

In summer, the chosen system allocates the largest weight to same day $\mathrm{PM}_{2.5}$ and equal weights to the two days of $\mathrm{O}_{x}$. This is reversed in winter where the largest weight is the same day $\mathrm{O}_{\mathrm{x}}$, while the two days of $\mathrm{PM}_{2.5}$ have equal weights. Note that this is consistent with the lag-response relationships shown in Figure 1. The thresholds found for summer are $s_{P M 2.5}=31 \mu \mathrm{g} / \mathrm{m}^{3}$ and $s_{O x}=43 \mathrm{ppb}$ and are much lower for winter at the values $s_{P M 2.5}=25 \mu \mathrm{g} / \mathrm{m}^{3}$ and $s_{O X}=26 \mathrm{ppb}$.

The sensitivity and false alarms criteria show that the system has better performances in summer. Indeed, in summer, seven out of the eight episodes ( $87.5 \%)$ are detected by the system. As shown in Table S5 (Supplementary Materials), we preferred to miss one of the episodes to obtain a lower amount of false alarms. This missed episode is the 5th one (in July 2004) and is borderline since it shows a maximum EM of $51 \%$ while the preliminary threshold is at $s_{O M}=50 \%$. Note that it corresponds to a particularly dry (relative humidity of $55 \%)$ and hot $\left(T_{\max }=30^{\circ} \mathrm{C}\right)$ day. With the chosen system, only 1.5 false episodes are launched each year.

In winter, a system detecting only five out of the seven episodes is chosen, since it allows to launch half the number of false alarms than systems with better sensitivities (see Table S6 in Supplementary Materials). The two missed episodes are the 2nd and 5th one of January 2006 and 2013. Note that during the 5th episode, temperature is positive, which is unusual in January. The chosen system leads to an average of eight false alarms clustered in 3.7 false episodes per year. This system is thus less powerful than the summer one.

Table 3. Results for indicator weightings and thresholds for Montreal and Quebec. FA = false alarm.

\begin{tabular}{ccccccccccccc}
\hline \multirow{2}{*}{ City } & \multirow{2}{*}{ Season } & \multicolumn{3}{c}{$\mathbf{P M}_{\mathbf{2 . 5}}\left(\boldsymbol{\mu} \mathbf{g} / \mathbf{m}^{\mathbf{3}}\right)$} & \multicolumn{3}{c}{$\mathbf{O}_{\mathbf{x}}(\mathbf{p p b})$} & \multicolumn{2}{c}{ Sensitivity $(\%)$} & \multicolumn{2}{c}{ FA per Year } \\
\cline { 3 - 12 } & & $\boldsymbol{\alpha}_{0}$ & $\boldsymbol{\alpha}_{1}$ & $\boldsymbol{s}$ & $\boldsymbol{\alpha}_{0}$ & $\boldsymbol{\alpha}_{1}$ & $\boldsymbol{s}$ & Days & Episodes & Days & Episodes \\
\hline \multirow{2}{*}{ Montreal } & Summer & 0.9 & 0.1 & 31 & 0.5 & 0.5 & 43 & 22.4 & 87.5 & 3.1 & 1.5 \\
& Winter & 0.5 & 0.5 & 25 & 0.8 & 0.2 & 26 & 15.4 & 71.4 & 8.0 & 3.7 \\
\hline \multirow{2}{*}{ Quebec City } & Summer & 0.5 & 0.5 & 32 & 0.8 & 0.2 & 23 & 20.4 & 85.7 & 4.7 & 2.6 \\
& Winter & 0.5 & 0.5 & 33 & 0.7 & 0.3 & 21 & 9.5 & 50 & 15.5 & 7.4 \\
\hline
\end{tabular}

Table 3 also shows the final APHWS chosen in Quebec City. Indicators for both summer and winter are similar to indicators for winter in Montreal, i.e., equal weights for $\mathrm{PM}_{2.5}$ and larger weight on the same day for $\mathrm{O}_{\mathrm{x}}$. The thresholds found for $\mathrm{PM}_{2.5}$ are similar to the summer system at Montreal at $s_{P M 2.5}=32 \mu \mathrm{g} / \mathrm{m}^{3}$ for summer and $s_{P M 2.5}=33 \mu \mathrm{g} / \mathrm{m}^{3}$ for winter, but the thresholds for $\mathrm{O}_{\mathrm{x}}$ are much lower at $s_{O x}=23$ and $21 \mathrm{ppb}$. The main difference is nonetheless in the performances, much lower in Quebec City than in Montreal. The sensitivities are overall lower and the number of false alarms higher.

\subsection{Sensitivity Analysis}

The variables and lags used to construct indicators are chosen based on prior knowledge of the relationship between atmospheric pollutants and mortality. However, it is of interest to evaluate the sensitivity of the APHWS to each variable and to the choice of lags. In this regard, Figure 4 shows the sensitivity versus the number of FA for different choices of variables and lags in Montreal. Variables are either $\mathrm{PM}_{2.5}$ alone, $\mathrm{O}_{\mathrm{x}}$ alone, or both, as considered in Section 3.1. Lags are either $L=1$ as in Section 3.1 or $L=2$ to evaluate whether adding a day of lag would strengthen the APHWS. The closer to the upper left corner the curve, the better the APHWS. Note that this is similar to the well-known 
receiver operating characteristic (ROC) curves and thus we will refer to Figure 4 as ROC curves in the following.

a) Summer

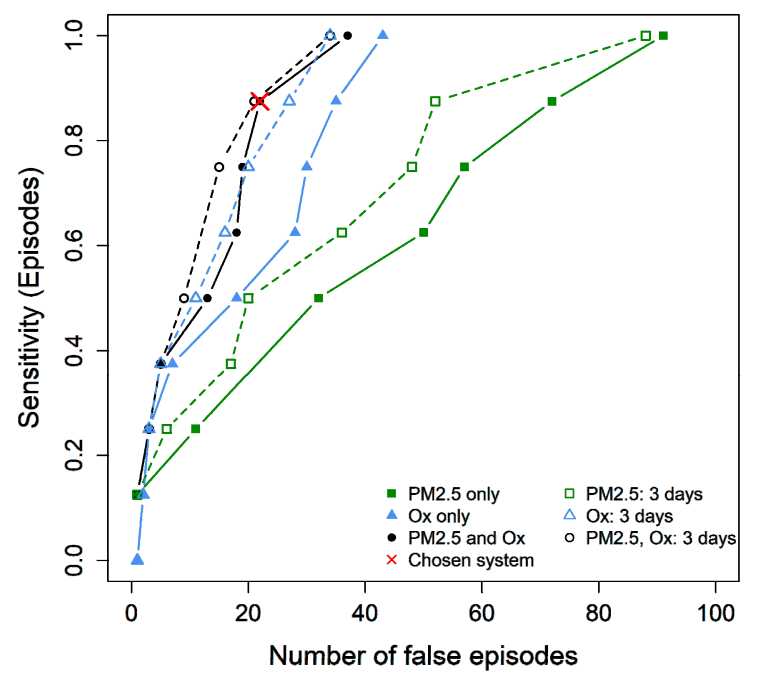

b) Winter

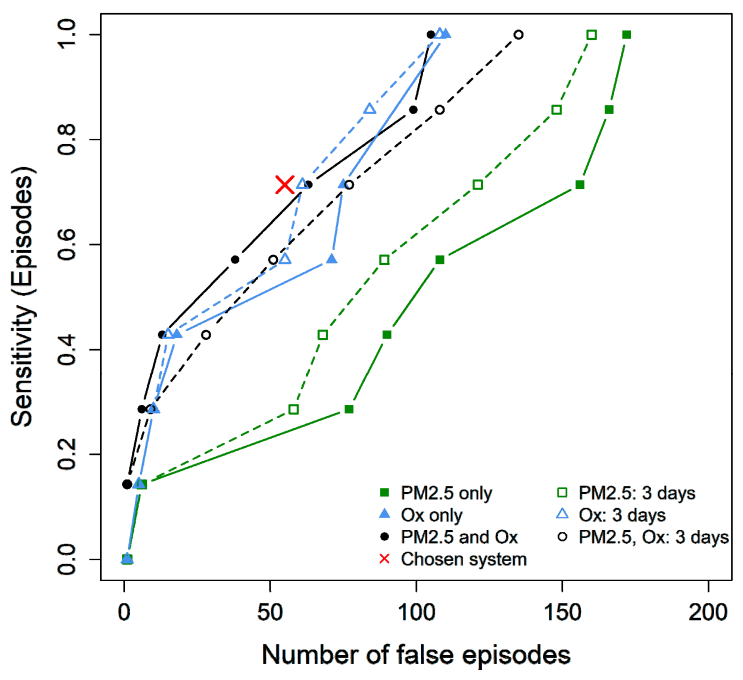

Figure 4. Receiver operating characteristic (ROC) curves for different variables used in the air pollution-health warning system (APHWS). For a type of APHWS, each point corresponds to the result of a particular weighting and threshold couple. The points reported here correspond to likely choices, i.e., to the best trade-offs between sensitivity and false alarms. Filled symbols correspond to APHWS with two-day indicators, and empty symbols to APHWS with three-day indicators. The red cross corresponds to the system of Table 3.

Figure 4 shows that the APHWS is more sensitive to the presence of $\mathrm{O}_{x}$ than to the presence of $\mathrm{PM}_{2.5}$. Indeed, an APHWS with only $\mathrm{O}_{\mathrm{x}}$ shows a ROC curve close to the APHWS with both variables, while an APHWS with only $\mathrm{PM}_{2.5}$ shows lower performances. This difference is more prominent in summer than winter, suggesting an important impact of $O_{x}$ in summer. This result also strengthens the choice to consider $\mathrm{O}_{x}$ in the APHWS.

Regarding the lag, Figure 4 shows that an APHWS using indicators with $L=2$ have overall ROC curves slightly closer to the upper left corner than their $L=1$ counterparts. The only exception is the system with two indicators in winter, showing a ROC curve above its $L=2$ counterpart. The difference is not important for APHWS with high thresholds (low sensitivity and false alarms) but grows as the sensitivity and number of false alarms increase. Therefore, the ROC curves suggest that considering $L=2$ could only marginally increase the APHWS's strength. This legitimates the choice of $L=1$ by showing that increasing it would not really improve the APHWS

\section{Discussion}

Many organizations have established air quality guidelines at different scales, such as the World Health Organization (WHO) at the global scale, Environment and Climate Change Canada (ECCC) for the country, the Ministère du Développement Durable de l'Environnement et de la Lutte contre les Changement Climatiques (MDDELCC) for the province of Quebec, and the Réseau de Surveillance de la Qualite de l'Air (RSQA) for the sole city of Montreal (about half the metropolitan area). One has to keep in mind that those guidelines are specific to the geographic level of management. For instance, decision makers should consider the Montreal value for the population of Montreal city, and the Province of Quebec values for the population in other locations of the province. Provincial values are mandatory, Canadian Ambient Air Quality Standards are recommendations based of health risk evaluation and technical feasibility of risk management, while the WHO guidelines are health-based values that do not consider management issues. The guidelines issued by these organizations are 
shown in Table 4 for comparison with our results. Note that no guidelines exist for $\mathrm{O}_{\mathrm{x}}$, and the ones reported are (rough) estimations from guidelines for $\mathrm{O}_{3}$ and $\mathrm{NO}_{2}$ using the formula in Section 2.1 and should not be seen as standard.

The threshold values found for short-term exposures to $\mathrm{PM}_{2.5}\left(31 \mu \mathrm{g} / \mathrm{m}^{3}\right.$ and $\left.25 \mu \mathrm{g} / \mathrm{m}^{3}\right)$ are in the range of the different guidelines. The summer threshold is close to the one considered in the province of Quebec while the winter one is closer to the WHO recommendation. However, the thresholds found for $\mathrm{O}_{\mathrm{x}}$ are much lower than the calculated guidelines. This may be explained by the different indicators which are based on very short-term exposure, while we hereby consider two-days means of maximum values. This could also be an indication that $\mathrm{O}_{\mathrm{x}}$ have an impact at lower values than expected.

In the case of Quebec City, no guideline existed specifically for the city before the present study. However, Table 4 shows that the $\mathrm{PM}_{2.5}$ thresholds for Quebec City are similar to the Montreal's ones and that the $\mathrm{O}_{x}$ thresholds are much lower than any values of the calculated guideline. Overall, the APHWS is less performant in Quebec City with more false alarms and lower sensitivity. This is due to the smaller population of Quebec City $(800,000$ versus around 4 million in Montreal, including metropolitan areas) which results in a lower amount of cardiovascular or respiratory mortality (a mean of three deaths per day). This makes setting an APHWS much more perilous since the response to an extreme AP exposure may be hidden in the day-to-day variations. This could explain the low values of $s_{O x}$ for which there may not be enough mortality to estimate its impact on the population.

Table 4. Sample of indicators and threshold guidelines from different organizations. ${ }^{*}$ estimated values of $\mathrm{O}_{\mathrm{x}}$ based on the guideline values of $\mathrm{O}_{3}$ and $\mathrm{NO}_{2}$ using the formula of Section 2.1.

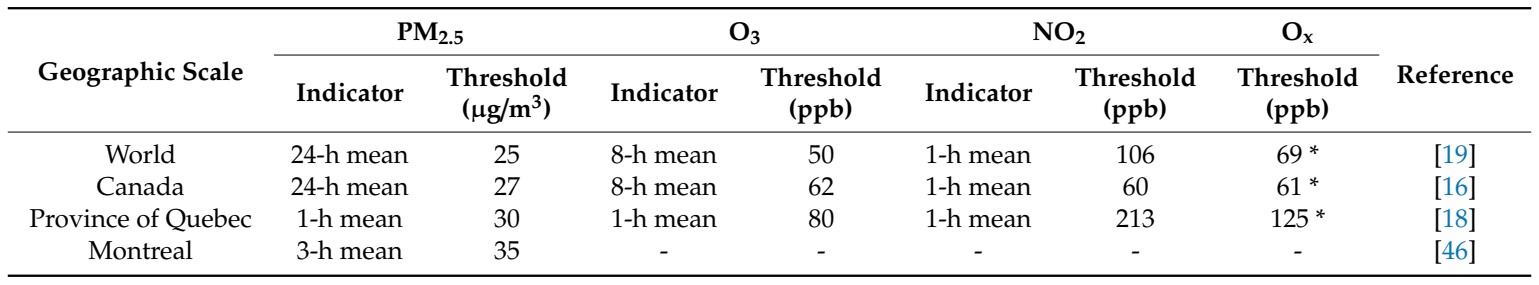

In summer, half of the determined episodes correspond to high temperature peaks (see Table S3) which could result in an overestimation of the response to smog episodes. This is consistent with the recent European study that showed a synergistic effect of hot temperature and air pollution on mortality [24]. However, note that in an operational context, we prefer risking overestimation of the mortality response rather than underestimation, especially since the APHWS is expected to be used jointly with the heat-health warning system. Finally, note that these episodes still correspond to important air pollution levels because of the preliminary threshold on $\mathrm{PM}_{2.5}\left(25 \mu \mathrm{g} / \mathrm{m}^{3}\right)$. Thus, they cannot reasonably be discarded from the analysis.

A number of limitations arise concerning the method considered for proposing the present APHWS. Indeed, the final indicators and threshold significantly depend on choices made in the preliminary steps of the method. For instance, extreme EM episodes linked to air pollution are determined using two predetermined and subjectively chosen thresholds: $s_{O M}$ and the preliminary threshold on $\mathrm{PM}_{2.5}$ $\left(25 \mu \mathrm{g} / \mathrm{m}^{3}\right)$. This may not be as adapted to air pollution as it is for heat waves, because of the seemingly linear mortality response to an air pollution exposure. This means that there are no values above which the relationship is stronger [47], in contrast with temperature for which minimum mortality intervals can be identified above which the risk is greatly increased [48]. In addition, although other variables, such as temperature, humidity and the day of season, can act as potential confounders, they are difficult to integrate to the methodology to choose thresholds and indicators.

Another limitation arises from the sole use of mortality as health issue as it is insufficient to represent the whole impact of smog episodes. Air pollution also impacts hospital admissions for instance [3]. However, hospital admissions do not allow for the detection of extreme impacts of smog the same way mortality does, as illustrated in Figure S5 (Supplementary Materials). Note that 
the APHWS could nonetheless be strengthened by also considering other data sources, such as the telephone service Info-Santé (811 in Quebec) or ambulance calls.

As a perspective, further methodological development is needed to estimate optimal indicators and threshold, accounting for the limitations exposed above. It could also be of interest to consider indicators similar to the WHO and ECCC guidelines, i.e., based on 1-h or 8-h maxima, rather than daily maxima. Indeed, the impact of $\mathrm{O}_{\mathrm{x}}$ in particular seems to be very short-term.

Of course, the proposed modifications in thresholds are not intended for use by the general public that would get confused with several coexisting thresholds. Our intention is rather to provide the decision-maker with a more precise assessment of potential harm during air pollution peak episodes in a specific urban area. This could lead, for instance, to more vigorous pollutant reduction measures, such as free public transit or speed limitations, to decrease peak levels of pollution for a limited time period. Indeed, air pollution is by far the most important and expensive risk in Canada [49].

\section{Conclusions}

The present study offers a starting point to develop an air pollution-health warning system in the cities of Montreal and Quebec City of the province of Quebec, Canada. Here, we propose initial indicators and thresholds to be monitored. The analysis and methodology used to establish the APHWS are inspired by the previous work concerning heat waves. It consists in first determining a level of excess mortality to be detected by the APHWS and then choosing the best air pollutant indicators and thresholds in order to launch relevant alarms. Depending on the city and season, thresholds found range between 25 and $33 \mu \mathrm{g} / \mathrm{m}^{3}$ for $\mathrm{PM}_{2.5}$ and between 21 and $43 \mathrm{ppb}$ for $\mathrm{O}_{\mathrm{x}}$. Thresholds on $\mathrm{PM}_{2.5}$ are consistent with the guidelines of different organizations, but more focused on extreme events and thus more accurate. However, thresholds on $\mathrm{O}_{\mathrm{x}}$ are lower than expected which could indicate that further research on its impact may be needed. The thresholds will be implemented in the real-time Surveillance and Prevention of the impacts of Extreme Meteorological Events on public health (SUPREME) system of the Institut National de Santé Publique du Québec [50] in order to alert public health stakeholders and, eventually, hospital administrators.

This study also reminds us that using internationally set thresholds may underestimate the specific dose-response relationship that exists in a specific context. The actual health impacts in a given area takes into account the local nature of the pollutants, their dispersion, the sensitivity of the local population given its demographics and health status, and their various behaviors that can augment or reduce exposure. Such adapted thresholds could also speak more to local decision-makers as they reflect the health impacts of their citizens. More studies examining the cost-benefits involved would be of interest to implement such an approach more widely [51].

Supplementary Materials: The following are available online at http://www.mdpi.com/1660-4601/16/12/2095/s1, Figure S1: Lag-response relationship between mortality in Quebec City and (a) $\mathrm{PM}_{2.5}$ and (b) $\mathrm{O}_{3}$. Figure S2: Number of excess mortality (EM) episodes according to the chosen preliminary EM threshold $s_{O M}$ for Quebec City. Figure S3: EM series with the identification of EM episodes for Quebec City. Figure S4: DLNM surfaces obtained between mortality and $\mathrm{PM}_{2.5}$ as well as $\mathrm{O}_{\mathrm{x}}$ for $(\mathrm{a}, \mathrm{b})$ summer and (c, d) winter. Figure S5: Excesses of cardiovascular and respiratory (a) hospital admissions and (b) the sum of hospital admission and deaths for summer in Montreal as an example. Table S1: Best weights and threshold candidates for the summer air pollution-health warning system (APHWS) in Quebec City. Table S2: Best weights and threshold candidates for the winter APHWS in Quebec City. Table S3: Episodes with EM $>50 \%$ and $\mathrm{PM}_{2.5} \max >25 \mu \mathrm{g} / \mathrm{m}^{3}$ for the summer APHWS in Montreal. Table S4: Episodes with $\mathrm{EM}>40 \%$ and $\mathrm{PM}_{2.5} \max >25 \mu \mathrm{g} / \mathrm{m}^{3}$ for the winter APHWS in Montreal. Table S5: Best weights and threshold candidates for the summer APHWS in Montreal. Table S6: Best weights and threshold candidates for the winter APHWS in Montreal.

Author Contributions: P.M.: software, formal analysis, writing—original draft preparation, visualization; F.C.: conceptualization, methodology, writing - review and editing, supervision, project administration, funding acquisition; É.L.: validation, writing—review and editing; C.C.: conceptualization, validation, writing-review and editing, funding acquisition; P.G.: validation, writing — review and editing; T.O. writing—review and editing, funding acquisition.

Funding: This research received no external funding. 
Acknowledgments: The authors warmly thank Charlotte Billy for its contribution in paving the way of the present paper. In addition, the authors want to thank Jean-Xavier Giroux and Christian Filteau for kindly extracting all the necessary data from the different sources. The authors also want to thank the Institut National de Santé Publique du Québec (INSPQ) and the Ouranos consortium for funding this study. The authors are grateful to three anonymous reviewers for their help in improving the quality of the paper. All analyses are performed using the open source $\mathrm{R}$ software, with the addition of the package $d \operatorname{lnm}$. The R code used to generate all the results and figures can be found on the corresponding author's github page (https://github.com/PierreMasselot).

Conflicts of Interest: The authors declare no conflict of interest.

\section{References}

1. World Health Organization. Review of Evidence on Health Aspects of Air Pollution-REVIHAAP Project; World Health Organization: Geneva, Switzerland, 2013.

2. Dominici, F.; Peng, R.D.; Bell, M.L.; Pham, L.; McDermott, A.; Zeger, S.L.; Samet, J.M. Fine Particulate Air Pollution and Hospital Admission for Cardiovascular and Respiratory Diseases. JAMA 2006, 295, 1127-1134. [CrossRef] [PubMed]

3. Requia, W.J.; Adams, M.D.; Arain, A.; Papatheodorou, S.; Koutrakis, P.; Mahmoud, M. Global Association of Air Pollution and Cardiorespiratory Diseases: A Systematic Review, Meta-Analysis, and Investigation of Modifier Variables. Am. J. Public Health 2018, 108, S123-S130. [CrossRef] [PubMed]

4. Achilleos, S.; Kioumourtzoglou, M.-A.; Wu, C.-D.; Schwartz, J.D.; Koutrakis, P.; Papatheodorou, S.I. Acute effects of fine particulate matter constituents on mortality: A systematic review and meta-regression analysis. Environ. Int. 2017, 109, 89-100. [CrossRef] [PubMed]

5. Vodonos, A.; Awad, Y.A.; Schwartz, J. The concentration-response between long-term $\mathrm{PM}_{2.5}$ exposure and mortality: A meta-regression approach. Environ. Res. 2018, 166, 677-689. [CrossRef] [PubMed]

6. Medina-Ramón, M.; Schwartz, J. Who is More Vulnerable to Die from Ozone Air Pollution? Epidemiology 2008, 19, 672-679. [CrossRef] [PubMed]

7. Mills, I.C.; Atkinson, R.W.; Kang, S.; Walton, H.; Anderson, H.R. Quantitative systematic review of the associations between short-term exposure to nitrogen dioxide and mortality and hospital admissions. BMJ Open 2015, 5, e006946. [CrossRef] [PubMed]

8. Brook, R.D.; Rajagopalan, S.; Pope, C.A.; Brook, J.R.; Bhatnagar, A.; Diez-Roux, A.V.; Holguin, F.; Hong, Y.; Luepker, R.V.; Mittleman, M.A.; et al. Particulate Matter Air Pollution and Cardiovascular Disease: An Update to the Scientific Statement From the American Heart Association. Circulation 2010, 121, 2331-2378. [CrossRef] [PubMed]

9. Cascio, W.E. Wildland fire smoke and human health. Sci. Total Environ. 2018, 624, 586-595. [CrossRef]

10. Reid, C.E.; Brauer, M.; Johnston, F.H.; Jerrett, M.; Balmes, J.R.; Elliott, C.T. Critical Review of Health Impacts of Wildfire Smoke Exposure. Environ. Health Perspect. 2016, 124, 1334-1343. [CrossRef]

11. Castner, J.; Guo, L.; Yin, Y. Ambient air pollution and emergency department visits for asthma in Erie County, New York 2007-2012. Int. Arch. Occup. Environ. Health 2018, 91, 205-214. [CrossRef]

12. Tétreault, L.-F.; Doucet, M.; Gamache, P.; Fournier, M.; Brand, A.; Kosatsky, T.; Smargiassi, A.; Tétreault, L.-F.; Doucet, M.; Gamache, P.; et al. Severe and Moderate Asthma Exacerbations in Asthmatic Children and Exposure to Ambient Air Pollutants. Int. J. Environ. Res. Public Health 2016, 13, 771. [CrossRef] [PubMed]

13. Kelly, F.J.; Fuller, G.W.; Walton, H.A.; Fussell, J.C. Monitoring air pollution: Use of early warning systems for public health. Respirology 2012, 17, 7-19. [CrossRef] [PubMed]

14. Li, C.; Zhu, Z. Research and application of a novel hybrid air quality early-warning system: A case study in China. Sci. Total Environ. 2018, 626, 1421-1438. [CrossRef]

15. Jiang, P.; Li, C.; Li, R.; Yang, H. An innovative hybrid air pollution early-warning system based on pollutants forecasting and Extenics evaluation. Knowl.-Based Syst. 2019, 164, 174-192. [CrossRef]

16. Environment and Climate Change Canada. Canadian Environmental Sustainability Indicators: Air Quality; Environment and Climate Change Canada: Gatineau, PQ, Canada, 2018.

17. Stieb, D.M.; Burnett, R.T.; Smith-Doiron, M.; Brion, O.; Shin, H.H.; Economou, V. A New Multipollutant, No-Threshold Air Quality Health Index Based on Short-Term Associations Observed in Daily Time-Series Analyses. J. Air Waste Manag. Assoc. 2008, 58, 435-450. [CrossRef] [PubMed] 
18. Ministère du Développement Durable, Environnement et Lutte contre les Changements Climatiques Indice de la qualité de l'air. Available online: http://www.iqa.mddefp.gouv.qc.ca/contenu/calcul.htm (accessed on 12 October 2018).

19. Xu, Y.; Yang, W.; Wang, J. Air quality early-warning system for cities in China. Atmos. Environ. 2017, 148, 239-257. [CrossRef]

20. World Health Organization. WHO Air Quality Guidelines for Particulate Matter, Ozone, Nitrogen Dioxide and Sulfur Dioxide: Global Update 2005; World Health Organization: Geneva, Switzerland, 2006.

21. Atkinson, R.W.; Kang, S.; Anderson, H.R.; Mills, I.C.; Walton, H.A. Epidemiological time series studies of PM2.5 and daily mortality and hospital admissions: A systematic review and meta-analysis. Thorax 2014, 69, 660-665. [CrossRef]

22. Rodriguez-Villamizar, L.A.; Magico, A.; Osornio-Vargas, A.; Rowe, B.H. The effects of outdoor air pollution on the respiratory health of Canadian children: A systematic review of epidemiological studies. Can. Respir. J. 2015, 22, 282-292. [CrossRef]

23. Wang, C.; Tu, Y.; Yu, Z.; Lu, R. PM 2.5 and Cardiovascular Diseases in the Elderly: An Overview. Int. J. Environ. Res. Public Health 2015, 12, 8187-8197. [CrossRef]

24. Analitis, A.; de' Donato, F.; Scortichini, M.; Lanki, T.; Basagana, X.; Ballester, F.; Astrom, C.; Paldy, A.; Pascal, M.; Gasparrini, A.; et al. Synergistic Effects of Ambient Temperature and Air Pollution on Health in Europe: Results from the PHASE Project. Int. J. Environ. Res. Public Health 2018, 15, 1856. [CrossRef]

25. Cairncross, E.K.; John, J.; Zunckel, M. A novel air pollution index based on the relative risk of daily mortality associated with short-term exposure to common air pollutants. Atmos. Environ. 2007, 41, 8442-8454. [CrossRef]

26. Islam, M.S.; Chaussalet, T.J.; Koizumi, N. Towards a threshold climate for emergency lower respiratory hospital admissions. Environ. Res. 2017, 153, 41-47. [CrossRef] [PubMed]

27. Chebana, F.; Martel, B.; Gosselin, P.; Giroux, J.-X.; Ouarda, T.B. A general and flexible methodology to define thresholds for heat health watch and warning systems, applied to the province of Québec (Canada). Int. J. Biometeorol. 2013, 57, 631-644. [CrossRef] [PubMed]

28. Hajat, S.; Sheridan, S.C.; Allen, M.J.; Pascal, M.; Laaidi, K.; Yagouti, A.; Bickis, U.; Tobias, A.; Bourque, D.; Armstrong, B.G.; et al. Heat-Health Warning Systems: A Comparison of the Predictive Capacity of Different Approaches to Identifying Dangerously Hot Days. Am. J. Public Health 2010, 100, 1137-1144. [CrossRef] [PubMed]

29. Benmarhnia, T.; Bailey, Z.; Kaiser, D.; Auger, N.; King, N.; Kaufman, J.S. A Difference-in-Differences Approach to Assess the Effect of a Heat Action Plan on Heat-Related Mortality, and Differences in Effectiveness According to Sex, Age, and Socioeconomic Status (Montreal, Quebec). Environ. Health Perspect. 2016, 124, 1694-1699. [CrossRef] [PubMed]

30. Zimek, A.; Schubert, E.; Kriegel, H.-P. A survey on unsupervised outlier detection in high-dimensional numerical data. Stat. Anal. Data Min. ASA Data Sci. J. 2012, 5, 363-387. [CrossRef]

31. Bratsch, S.G. Standard Electrode Potentials and Temperature Coefficients in Water at 298.15 K. J. Phys. Chem. Ref. Data 1989, 18, 1-21. [CrossRef]

32. Lavigne, E.; Burnett, R.T.; Weichenthal, S. Association of short-term exposure to fine particulate air pollution and mortality: Effect modification by oxidant gases. Sci. Rep. 2018, 8, 16097. [CrossRef]

33. Williams, M.L.; Atkinson, R.W.; Anderson, H.R.; Kelly, F.J. Associations between daily mortality in London and combined oxidant capacity, ozone and nitrogen dioxide. Air Qual. Atmos. Health 2014, 7, 407-414. [CrossRef]

34. Allen, R.G.; Pereira, L.S.; Raes, D.; Smith, M. Crop Evapotranspiration: Guidelines for Computing Crop Water Requirements; FAO Irrigation and Drainage; FAO: Rome, Italy, 1998.

35. Statistics Canada Comparability of ICD-10 and ICD-9 for Mortality Statistics in Canada; Statistics Canada: Ottawa, ON, Canada, 2005.

36. Pascal, M.; Laaidi, K.; Ledrans, M.; Baffert, E.; Caserio-Schönemann, C.; Le Tertre, A.; Manach, J.; Medina, S.; Rudant, J.; Empereur-Bissonnet, P. France's heat health watch warning system. Int. J. Biometeorol. 2006, 50, 144-153. [CrossRef]

37. Gasparrini, A.; Armstrong, B.; Kenward, M.G. Distributed lag non-linear models. Stat. Med. 2010, 29, $2224-2234$. [CrossRef] [PubMed] 
38. Gasparrini, A.; Scheipl, F.; Armstrong, B.; Kenward, M.G. A penalized framework for distributed lag non-linear models. Biom 2017, 73, 938-948. [CrossRef] [PubMed]

39. Gasparrini, A.; Guo, Y.; Hashizume, M.; Kinney, P.L.; Petkova, E.P.; Lavigne, E.; Zanobetti, A.; Schwartz, J.D.; Tobias, A.; Leone, M.; et al. Temporal Variation in Heat-Mortality Associations: A Multicountry Study. Environ. Health Perspect. 2015, 123, 1200-1207. [CrossRef] [PubMed]

40. Buteau, S.; Goldberg, M.S.; Burnett, R.T.; Gasparrini, A.; Valois, M.-F.; Brophy, J.M.; Crouse, D.L.; Hatzopoulou, M. Associations between ambient air pollution and daily mortality in a cohort of congestive heart failure: Case-crossover and nested case-control analyses using a distributed lag nonlinear model. Environ. Int. 2018, 113, 313-324. [CrossRef] [PubMed]

41. Chiu, Y.; Chebana, F.; Abdous, B.; Bélanger, D.; Gosselin, P. Mortality and morbidity peaks modeling: An extreme value theory approach. Stat. Methods Med. Res. 2016, 0962280216662494. [CrossRef] [PubMed]

42. Bustinza, R.; Lebel, G.; Gosselin, P.; Belanger, D.; Chebana, F. Health impacts of the July 2010 heat wave in Quebec, Canada. BMC Public Health 2013, 13, 56. [CrossRef]

43. Jhun, I.; Fann, N.; Zanobetti, A.; Hubbell, B. Effect modification of ozone-related mortality risks by temperature in 97 US cities. Environ. Int. 2014, 73, 128-134. [CrossRef] [PubMed]

44. Giroux, J.-X.; Chebana, F.; Gosselin, P.; Bustinza, R. Indicateurs et valeurs-seuils météorologiques pour les systèmes de veille-avertissement canicule pour le Québec: Mise à jour de l'étude de 2010 et développement d'un logiciel de calcul pour les systèmes d'alerte; Institut National de la Santé Publique du Québec: Quebec City, PQ, Canada, 2017; p. 62.

45. Sapkota, A.; Symons, J.M.; Kleissl, J.; Wang, L.; Parlange, M.B.; Ondov, J.; Breysse, P.N.; Diette, G.B.; Eggleston, P.A.; Buckley, T.J. Impact of the 2002 Canadian forest fires on particulate matter air quality in Baltimore city. Environ. Sci. Technol. 2005, 39, 24-32. [CrossRef]

46. Réseau de surveillance de la qualité de l'air. Environmental Assessment Report 2017: Air Quality in Montreal; Service de l'Environnement: Montreal, QC, Canada, 2017.

47. Koop, G.; Tole, L. An investigation of thresholds in air pollution-mortality effects. Environ. Model. Softw. 2006, 21, 1662-1673. [CrossRef]

48. Gasparrini, A.; Guo, Y.; Hashizume, M.; Lavigne, E.; Zanobetti, A.; Schwartz, J.; Tobias, A.; Tong, S.; Rocklöv, J.; Forsberg, B.; et al. Mortality risk attributable to high and low ambient temperature: A multicountry observational study. Lancet 2015, 386, 369-375. [CrossRef]

49. Smith, R.; McDougal, K. Costs of Pollution in Canada: Measuring the Impacts on Families, Businesses and Governments; International Institute for Sustainable Development: Winnipeg, MB, Canada, 2017; p. 145.

50. Toutant, S.; Gosselin, P.; Bélanger, D.; Bustinza, R.; Rivest, S. An Open Source Web Application for the Surveillance and Prevention of the Impacts on Public Health of Extreme Meteorological Events: The SUPREME System. Int. J. Health Geogr. 2011, 10, 39. [CrossRef] [PubMed]

51. Voorhees, S.S.; Sakai, R.; Araki, S.; Sato, H.; Otsu, A. Cost-Benefit Analysis Methods for Assessing Air Pollution Control Programs in Urban Environments-A Review. Environ. Health Prev. Med. 2001, 6, 63-73. [CrossRef] [PubMed]

(C) 2019 by the authors. Licensee MDPI, Basel, Switzerland. This article is an open access article distributed under the terms and conditions of the Creative Commons Attribution (CC BY) license (http://creativecommons.org/licenses/by/4.0/). 